\title{
Household size is associated with unintelligible speech in children who have intellectual disabilities: A South African study
}

Dana K. Donohue, Ph.D. ${ }^{1,}$ Juan Bornman, ${ }^{* 1,}$ Mats Granlund, Ph.D. ${ }^{2}$

Centre for Augmentative and Alternative Communication, University of Pretoria, Pretoria, South Africa, juan.bornman@up.ac.za*1,

CHILD, Jönköping University, Jönköping, Sweden ${ }^{2}$

Corresponding author: Juan Bornman juan.bornman@up.ac.za +27 124202001

Keywords: household size; intellectual disability; motor delays; risk factors; South Africa; unintelligible speech

\begin{abstract}
Objective: The purpose of this study was to examine whether four socioeconomic factors, namely caregiver age, caregiver education, family income, and/or household size were related to the presence of motor delays or unintelligible speech in South African children with intellectual disabilities.
\end{abstract}

Methods: Caregivers of children with intellectual disabilities completed a biographical questionnaire regarding their home environments. Other items on the questionnaire queried whether their children experienced the co-occurring developmental impairments of motor delays or unintelligible speech.

Results: A total of 145 caregivers were included in the analyses. Two logistic regressions were run with the set of four socioeconomic factors as predictors, and motor delays and intelligible 
speech as the outcome variables. Household size was a statistically significant predictor of whether children evidenced intelligible speech.

Conclusion: Children living in dwellings with more people were less likely to have intelligible speech. The processes through which large household size might influence children's language are discussed.

Keywords: household size; intellectual disability; motor delays; risk factors; South Africa; unintelligible speech.

\section{Introduction}

According to the American Association of Intellectual and Developmental Disabilities $(A A I D D)^{1}$, intellectual disability occurs when individuals experience significant limitations in adaptive behaviour and intellectual functioning, both beginning before 18 years of age. The majority of children with intellectual disabilities evidence less pronounced, or mild to moderate intellectual disabilities, and often there is no clear origin of their disabilities ${ }^{1}$. Statistics SA ${ }^{2}$ reported in 2001 that about $5 \%$ of the South African population had a disability, and of those individuals, $12,4 \%$ had an intellectual disability. Children with intellectual disabilities are often exposed to co-occurring conditions. According to Rosenberg and Abbeduto $^{3}$, delays in language development are common in this population. While it is often assumed that slow cognitive growth can affect language development, language deficits also may inhibit cognitive growth because words and sentences provide people with the means of complex thought ${ }^{4}$. In other words, language not only provides a way of 
communicating with others, but also a means of thinking. Co-occurring deficits in social skills ${ }^{5}$ that may encourage social isolation, as well as physical delays ${ }^{6}$ as a result of restrictions in participation (particularly in social and recreational activities ${ }^{7}$ ) are also often experienced by individuals with intellectual disabilities. These co-occurring conditions may aggravate or be aggravated by living in a poverty setting.

Zigler and Hodapp ${ }^{8}$ suggested that while mothers from varying socioeconomic backgrounds have children with congenital disabilities at similar rates, children with less pronounced intellectual disabilities disproportionally reside in families who live in poverty. While tracking a sample of low birth weight infants from different socioeconomic strata who all evidenced typical intelligence at birth, Escalona ${ }^{9}$ found, for example, that at 28 months of age, children living in impoverished homes experienced significant cognitive declines when compared to their more economically advantaged same-age peers. This intellectual gap persisted when the children were again assessed at 40 months of age. Determining the processes through which poverty influences children's intelligence is ongoing, but many researchers ${ }^{10,11}$ agree that parenting behaviours likely mediate this relationship. Stressors and frustrations that arise from residing in poverty, for example, can compromise parenting behaviours and prevent children from receiving the needed attention and intellectual stimulation that promote their development.

McGrath and Akoojee ${ }^{12}$ report that impoverishment affects about $45 \%$ to $55 \%$ of the South African population. One consequence of living in poverty can be household crowding, or too many residents in one living space. Household crowding tends to be negatively related to children's cognitive and language development ${ }^{13}$. Evans and colleagues ${ }^{14}$ determined that 
families who lived in crowded homes spoke less and used less complex and sophisticated language with their children when compared to families who lived in less crowded homes. Less exposure to language in their early years of development negatively influences children's subsequent vocabulary and $\mathrm{IQ}^{15}$.

Other socioeconomic factors that can affect child development include the caregiver age ${ }^{16}$, caregiver education, and family income ${ }^{17}$. A 2005 report by the Nelson Mandela Foundation ${ }^{18}$ found that low income South African families often cannot afford the resources associated with optimal conditions for their children's development. These financial difficulties can be amplified when families have a child with one or multiple disabilities who may require additional healthcare services. Young caregivers with relatively little education, moreover, may not have the knowledge or be empowered to provide optimal care and learning conditions ${ }^{19}$ for their children with disabilities.

Pinpointing the factors that influence the development of children with intellectual disabilities may help in the early identification of children who are at risk for co-occurring conditions and may expedite the development of interventions. The aim of this research was to determine whether socioeconomic factors increased the odds of South African children with intellectual disabilities exhibiting the co-occurring conditions of motor delay and/or unintelligible speech. The socioeconomic factors available for analysis in this research were caregiver age, caregiver education, household size and family income.

\section{Method}

Ethical clearance for conducting this study was obtained from the relevant higher education institution. Formal permission was also obtained from the appropriate South 
African Provincial Departments of Education, as well as from the school principals and the children's primary caregivers. This study forms part of a larger study that examined parental and child perspectives about the realisation of the rights of children with intellectual disabilities in South Africa ${ }^{20}$ in accordance with the United Nations Convention on the Rights of Children ${ }^{21}$.

\section{Participants}

A multiphase sampling procedure was followed, as provinces were first selected, followed by schools, and finally the children who met the selection criteria. The principals of government-funded special schools for children with mild to moderate intellectual disabilities in three provinces of South Africa were contacted and informed about the study. A total of 11 schools comprising seven schools in Gauteng, three in KwaZulu-Natal and one in Limpopo agreed to participate. Principals were asked to identify classrooms in which children with intellectual disabilities between 8 and 14 years of age were taught as possible participants in the larger study. The children could evidence co-occurring conditions, however with the exception of sensory impairments (e.g. blindness or deafness). Parental consent forms and biographical questionnaires were distributed via the classroom teacher. The data focused on the biographical factors related to socioeconomic status and child characteristics.

Of the 232 consent forms and biographical questionnaires that were sent out, 188 were returned by children's primary caregivers, resulting in a high return rate (81.03\%). Of these, 43 were however found to be missing data on at least one relevant variable for the required analyses. Little's MCAR test suggested the data were missing completely at random 
$\chi 2(2)=3.00, p=0.22$. These data were deleted listwise. The final sample consisted of data from 145 primary caregivers of children with intellectual disabilities.

The respondents primarily consisted of the mothers $(n=96)$ and fathers $(n=30)$ of the children, but a significant proportion of the sample listed themselves as 'other' $(n=19)$, which includes caregivers such as grandparents, aunts and older siblings. There was extreme diversity in the home languages of the participants: Afrikaans $(n=42)$; Nguni languages $(n=$ 39) $\{$ comprising isiZulu $(n=37)$, SiSwati $(n=1)$, isiXhosa $(n=1)\}$; Sotho languages $(n=34)$ \{comprising Sesotho $(n=22)$, Sepedi $(n=9)$, Setswana $(n=3)\}$; Xitsonga $(n=16)$; and English $(n=14)$. It should however be noted that almost all South Africans are multilingual and fluent in two or more of these languages ${ }^{24}$. Caregivers ranged from 22 to 67 years of age (mean age of 39.43 years) and they lived in households that ranged in size from 2 to 13 individuals (mean $=5.08$ people). Most of the caregivers had an education of Grade 10 or less $(n=72)$ and lived in households with total familial incomes of less than R60 000 (approximately $\$ 7500)$ per year $(n=93)$. The descriptive statistics for the four predictor variables (i.e. caregiver age, caregiver education, household size and family income) are summarised in Table 1. 
Household size and unintelligible speech

Table 1. Participant descriptive and percentage who said 'yes' to the outcome variables $(\mathrm{n}=145)$.

Caregiver age $\quad 22-67$ years $\quad \mathrm{M}=39.43 \quad \mathrm{SD}=8.56$

\begin{tabular}{|c|c|c|c|c|c|c|c|}
\hline \multirow{4}{*}{$\begin{array}{l}\text { Caregiver } \\
\text { education }\end{array}$} & Grade 11 or less & Grade 12 & & $1-4$ years & & 5-7 years after & $8-10$ years \\
\hline & $\mathrm{n}=72$ & & $n=$ & after high & & high school & after high \\
\hline & & 47 & & school & $\mathrm{n}$ & $\mathrm{n}=7$ & school \\
\hline & & & & $=15$ & & & $=4$ \\
\hline
\end{tabular}

Household size $\quad$ 2-13 people $\quad \mathrm{M}=5.08 \quad \mathrm{SD}=2.00$

Family income Less than R60 000 per year $\quad n=93 \quad$ More than R60 000 per year $\quad n=52$

Outcome variables $\quad$ Percentage who said 'yes'

Does your child have delayed motor skills?

$69 \%$

Does your child have intelligible speech?

$83 \%$ 


\section{Measure and Procedure}

Children's caregivers were provided a custom-designed questionnaire that queried biographical factors related to their socioeconomic status such as caregiver age, caregiver education, household size and family income. Items related to the child also were asked, for example, whether the child experienced physical and/or motor delays and whether the child's disability was apparent at birth. These questions were based on the Ten Questions Questionnaire (TQQ), a standardised, rapid, low-cost screening measure that has been shown to have a high reliability in developing country contexts in a variety of languages ${ }^{23}$. The questionnaire was designed in English, and then translated following a blind-back procedure to ensure that all questionnaires could be provided to caregivers in the language of instruction at their children's schools (i.e. Afrikaans, English, Xitsonga or isiZulu) ${ }^{20}$. Caregivers returned the questionnaires to the classroom teachers who collated them and then handed them to a research assistant.

\section{Data analysis}

The data were analysed using SPSS 20.0. First, data were screened for accuracy of entry and multicollinearity of the predictor variables. The predictors were not found to be very highly correlated and therefore were appropriate to be entered as a set. Frequencies, ranges, means and standard deviations were computed for descriptive purposes. Logistic regressions were then run to determine whether familial socioeconomic items were related to two child-related developmental factors: whether the child evidenced gross motor delays and whether the child had intelligible speech. 
Household size and unintelligible speech

Table 2. Binary logistic regression analyses: Delays in motor development, intelligible speech $(n=145)$.

Variables

Intelligible speech

$\begin{array}{lcccc}\text { Caregiver age } & 0.02 & 0.46 & 1.02 & 0.97-1.07 \\ \text { Caregiver education } & -0.04 & 0.02 & 0.96 & 0.58-1.61 \\ \text { Family income } & 0.45 & 0.64 & 1.57 & 0.52-4.70 \\ \text { Household size } & \mathbf{- 0 . 2 2} & \mathbf{4 . 6 6} & \mathbf{0 . 8 0} & \mathbf{0 . 6 5}-\mathbf{0 . 9 8} \\ \text { Constant } & 1.51 & 1.27 & -- & --\end{array}$

Note: Bold font signifies $p \leq 0.05$; Reference category is no.
B

0.02

$-0.17$

$-0.47$

$-0.03$

1.32

Constant

Odds

1.02

$0.97-1.06$

Caregiver education

0.65

0.85

$0.56-1.27$

Family income

1.12

0.63

$0.27-1.48$

Household size

0.09

0.97

$0.81-1.17$

1.42 


\section{Results}

Table 1 shows the sample descriptives and the percentage of participants who replied 'yes' to the items on the questionnaire that were used as outcome variables for the logistic regression analyses. The results for the binary logistic regressions are shown in Table 2 . The outcome variables for all analyses were coded 0 for no and 1 for yes. Four socioeconomic factors were the predictors for all analyses: caregiver age, caregiver education, household size and family income. The parameter coefficients for logistic regressions provided the expected change in the outcome variable holding the other predictor variables constant. The confidence intervals provided a range of values that, if the data had been collected thousands of times, would include the correct parameter estimate $95 \%$ of the time ${ }^{24}$.

\section{Delays in motor development}

A test of the full model with all four predictors against a constant-only model was not statistically significant $(\chi 2(4)=4.58, \mathrm{p}=0.33)$ and Nagelkerke's pseudo $\left(\mathrm{R}^{2}=0.04\right)$ was small. Together they indicated that the predictors were not a good fit for a model trying to distinguish between children who evidenced delays in motor development and those who did not. Classification was marginal, with $0 \%$ without delays in motor development and $99 \%$ of those with delays in motor development correctly predicted, for an overall success rate of $68 \%$. Table 2 shows the parameters for each of the four predictors. None were statistically significant and a score of 1.00 fell between the $95 \%$ confidence intervals for all of the odds ratios, which indicated that changes in the values of the predictors were not associated with delays in motor development. 


\section{Intelligible speech}

Again a test of the full model with all four predictors against a constant-only model was non-significant $(\chi 2(4)=5.19, \mathrm{p}=0.27)$ and Nagelkerke's pseudo $\mathrm{R}^{2}=0.06$ indicated the predictors accounted for a small percentage of the variance in intelligible speech. Classification for the children with unintelligible speech was poor at $4 \%$, but good for those children who had intelligible speech at $99 \%$. There was an overall classification success rate of $83 \%$. Household size was a significant predictor of whether children had intelligible speech $-\chi^{2}(1, n=145)=$ 4.66, $\mathrm{p} \leq 0.05$. The odds ratio suggested that a one-person increase in household size decreased the odds of the child having intelligible speech by a factor of $0.80(95 \% \mathrm{CI}=0.65-0.98)$. Inverting the odds ratio allows for easier interpretation $(1 / 0.80=1.25)$. When inverted, the odds ratio indicates that for each one-person increase in household size, children were 1.25 times less likely to have intelligible speech.

\section{Discussion}

The results of this study suggest that of the four socioeconomic indicators, household size was the only statistically significant predictor related to co-occurring developmental factors in children with intellectual disabilities that had been examined.

Specifically, household size was found to be negatively related to whether children had intelligible speech. Other research ${ }^{13,14,26}$ likewise found that household crowding evidences a negative influence on child development. It should, however be noted that only $17 \%$ of the children in the sample had unintelligible speech. This was expected, as published prevalence figures estimate that $4 \%$ to $12 \%$ of school-aged children with intellectual disabilities who 
required intermittent to limited support were nonspeaking, while $92 \%$ to $100 \%$ who required extensive to pervasive support were nonspeaking ${ }^{25}$.

In this research, household size was found to have a negative impact on children's intelligible speech, where each increase in household size made it 1.25 (the inverse of 0.80 ) times less likely that the child would have intelligible speech. Evans and colleagues ${ }^{14}$ found that families in crowded homes tend to speak less and use less complex language with their children, which results in smaller vocabularies and lower IQs ${ }^{15}$. Lack of language exposure may explain, in part, the strong associations that have been found between household crowding and children's cognitive development ${ }^{13}$. Evans and colleagues ${ }^{13}$ tested their hypothesised development pathway where crowding $\rightarrow$ maternal responsiveness $\rightarrow$ child cognitive development in a small sample of American children 36 months of age $(n=80)$ and in a large sample of British children 36 months of age $(n=10050)$. In both studies they found that diminished maternal responsiveness mediated the strong negative link between household crowding and children's cognitive development. They suggested that, as a result of the unwanted social interaction, mothers socially withdraw and this can lead to them being less attentive to their children.

While the results of the current research suggest that similar processes may operate within families in South Africa, measures of caregiver responsiveness were not included. Therefore, the link between household size and children's unintelligible speech cannot be definitively attributed to the interactions between children and their caregivers. Future research exploring the impact of socioeconomic factors on the development of South African children with intellectual disabilities should include measures of potential processes (e.g. caregiver 
responsiveness, language exposure) through which children's environments affect their development.

\section{Limitations}

A limitation of the study was that the children with intellectual disabilities who were the target population in this study were all attending school. Although school attendance for all children in South Africa is compulsory, up to $70 \%$ of children with disabilities do not go to school $^{27}$. The reasons for this vary. Some parents find the added expense of school fees for their children with disabilities too much of a financial burden, particularly if they have non-disabled children they send to school. Additionally, the special schools for children with disabilities in South Africa can be far away from children's homes and the cost of transportation to school can become prohibitive. Some parents even prefer their children to stay home and help with the housework rather than to attend school. For all of these reasons and more, many children with disabilities in South Africa do not go to school. The results of the present study should therefore not be considered generalisable to families who do not send their children with disabilities to school.

Another limitation concerned the measures of household size and income. Although household size provided a count of how many people lived in the household, it did not give an indication of how large the housing structure was. It is possible that families with many household members had very large houses and therefore did not experience crowding. We argue, however, that this is unlikely, as most of the sample had total familial yearly incomes of less than R60 000 (approximately $\$ 7500 ; n=93$ ) and families cannot afford to live in large houses with this income. Even for those families with incomes higher than R60 000, large houses will 
probably be cost prohibitive. A more nuanced measure of income (e.g. more than two options, or a continuous measure of income) would perhaps provide more information about the relationship between income and household size, but such data was not available in this study.

Finally, the low proportion of non-speaking children makes the validity of the prediction lower. Fewer than 25 children in the sample were classified as without intelligible speech, which made the classification for the children without understandable speech in the model less reliable. However, the model classified children who did have intelligible speech at $99 \%$ and the model had an overall classification success rate of $83 \%$.

\section{Conclusions}

Impoverished living conditions are stressful and can hinder optimal parenting behaviours ${ }^{10}$. This study suggests that household size may be an important socioeconomic indicator of the development of children with intellectual disabilities in South Africa. Crowding may not only impede parenting ${ }^{13}$, but also may expose children to more environmental toxins than they would encounter if they lived in a less cramped housing structure ${ }^{28}$. Prevention of secondary impairments and early intervention can improve the developmental outcomes of children with disabilities. Interventions can emanate from various ecological levels. At a policy level, the South African government could try to provide its poorest citizens with decent and less crowded housing. Schools can train teachers to be cognisant of children who may be at risk in order to refer them for intervention services. At a family level, intervention should focus more on trying to improve the caregiver-child relationship, particularly the type of linguistic interactions and conversations that caregivers have with their children. Most families in South Africa and throughout the world want what is best for their children. If they are provided with 
understandable and appropriate information about how to foster the development of their children, they are likely to use that information to help their children and better the family wellbeing.

\section{Acknowledgements}

While the financial contribution of the Swedish International Development Cooperation Agency (SIDA) is gratefully acknowledged, the opinions and interpretations expressed here do not necessarily reflect those of SIDA.

\section{Declaration of Interests}

The authors report no conflict of interest. The authors alone are responsible for the content and writing of this paper.

\section{References}

[1]. American Association on Intellectual and Developmental Disabilities (AAIDD). Intellectual disability: Definition, classification, and systems of supports. Washington, DC: American Association on Intellectual and Developmental Disabilities; 2010.

[2]. Statistics SA. http://www.statssa.gov.za/publications/populationstats.asp. 2001. Retrieved November 12, 2012.

[3]. Rosenberg S, Abbeduto L. Language and Communication in Mental Retardation: Development, Process, and Intervention. Hillsdale, NJ: Lawrence Erlbaum Associates; 1993.

[4]. Buckley SJ, Bird G, Sacks B, Archer T. A comparison of mainstream and special education for teenagers with Down syndrome: Implications for parents and teachers. Down Syndrome Research and Practice 2006; 9:54-67. 
[5]. Smith KRM, Matson JL. Social skills: Differences among adults with intellectual disabilities, comorbid autism spectrum disorders and epilepsy. Research on Developmental Disabilities 2010; 31:1366-1372.

[6]. Matson ML, Matson JL, Beighley JS. Comorbidity of physical and motor problems in children with autism. Research in Developmental Disabilities 2011; 32: 2304-2308.

[7]. Shields N, King M, Corbett M, Imms C. Is participation among children with intellectual disabilities in outside school activities similar to their typically developing peers? A systematic review. Developmental Neurorehabilitation 2013; Early Online 1-8, DOI: $10.33109 / 17518423.2013 .836256$.

[8]. Zigler E, Hodapp RM. Understanding mental retardation. New York: Cambridge University Press; 1986.

[9]. Escalona, SK. Babies at double hazard: Early development of infants at biologic and social risk. Pediatrics 1982; 70:670-676.

[10]. Bradley RH, Whiteside L, Mundfrom DJ, Casey PH, Kelleher KJ, Pope SK. Early indications of resilience and their relation to experiences in the home environments of low birthweight, premature children living in poverty. Child Development 1994; 65:346-360.

[11]. Heckman JJ. The American family in Black and White: A post-racial strategy for improving skills to promote equality. Daedalus $2011 ; 140: 70-89$.

[12]. McGrath S, Akoojee S. Education and skills for development in South Africa: Reflections on the accelerated and shared growth initiative for South Africa. International Journal of Educational Development 2007; 27:421-434. 
[13]. Evans GW et al. Crowding and cognitive development: The mediating role of maternal responsiveness among 36-month-old-children. Environment and Behavior 2010; 42:135-148.

[14]. Evans GW, Maxwell L, Hart B. Parental language and verbal responsiveness to children in crowded homes. Developmental Psychology 1999; 35:1020-1023.

[15]. Hart B, Risley TR. Meaningful differences in the everyday experience of young American children. Baltimore: Brooks Publishing Company; 1995.

[16]. Emerson E. Poverty and people with intellectual disabilities. Mental Retardation and Developmental Disabilities Research Reviews 2007; 13:107-113. Doi:10.1002/mrdd.20144.

[17]. Grantham-McGregor S, Cheung YB, Cueto S, Glewwe P, Richter L, Strupp B. The International Child Development Steering Group. Developmental potential in the first 5 years for the children in developing countries. The Lancet 2007; 369: 60-70. DOI:10.101016/S0140-6736(07)60032-4.

[18]. Nelson Mandela Foundation. Emerging Voices: A Report on Education in South African Rural Communities. Pretoria: HSRC Press; 2005.

[19]. Casey MM, Call KT, Klinger JM. Are rural residents less likely to obtain recommended preventive health care services? American Journal of Preventive Medicine 2001; 21(3):182-188.

[20]. Donohue DK, Bornman J, Granlund M. Examining the rights of children with intellectual disability in South Africa: Children's perspectives. Journal of Intellectual and Developmental Disability 2013; 39:1, 55-64, DOI: 10.3109/13668250.2013.857769.

[21]. United Nations Convention on the Rights of the Child. United Nations; 1989.

[22]. Gonasillan A, Bornman J, Harty M. Vocabulary used by ethno-linguistically diverse South African toddlers: A parent report using the Language Development Survey. South African Journal of Communication Disability 2013; 60:10-15. 
Household size and unintelligible speech

[23]. Durkin MS, Hasan ZM, Hasan KZ. The ten questions screen for childhood disabilities:

Its uses and limitations in Pakistan. Journal of Epidemiology Community Health 1995; 49:431-436.

[24]. Wuensch KL. Binary logistic regression. East Carolina University, Department of Psychology; 2011.

[25]. Matas J, Mathy-Laikko P, Beukelman D, Legresley K. Identifying the nonspeaking population: A demographic study. Augmentative and Alternative Communication 1985; 1:17-31.

[26]. Evans GW, Saegert S, Harris R. Residential density and psychological health among children in low-income families. Environment and Behavior 2001; 33:165-180.

[27]. Department of Education. White Paper 6: Building an inclusive education and training system. Pretoria: Government Printers; 2001.

[28]. Baker M, Das D, Venugopal K, Howden-Chapman P. Tuberculosis associated with household crowding in a developed country. Journal of Epidemiological Community Health 2008; 62:715-721. 